\title{
A DISCRIMINAÇÃO HOMOFÓBICA POR MEIO DO HUMOR: NATURALIZAÇÃOE MANUTENÇÃO DA HETERONORMATIVIDADE NO CONTEXTO ORGANIZACIONAL
}

\author{
Homophobic discrimination through humor: naturalization and \\ heteronormativity maintenance in the organizational context
}

\author{
Samira Loreto Edilberto Pompeu* \\ Eloisio Moulin de Souza**
}

\section{RESUMO}

Esta pesquisa está inserida no âmbito dos estudos sobre diversidade sexual nas organizações, delimitada na temática do humor homofóbico. Buscou-se analisar se o humor homofóbico está presente no ambiente de trabalho e de que forma. Orientado por uma perspectiva interpretativista, o artigo se fundamenta em estudos sobre a discriminação por homofobia e humor, assim como sobre a heteronormatividade nas organizações. Para cumprir seu objetivo foi realizada análise de conteúdo de entrevistas efetuadas com funcionários homossexuais, bissexuais e heterossexuais de uma empresa. Constatou-se a presença do humor homofóbico frequente; do humor homofóbico naturalizado; das piadas homofóbicas como discursos para manter a heteronormatividade. Percebe-se um cenário no qual carece de ações que promovam a diversidade, especialmente no que tange à questão do humor, bem como da falta do entendimento por parte de trabalhadores de que piadas de humor homofóbico estão ligadas à opressão. Este artigo contribui no aprofundamento dos estudos nacionais sobre humor homofóbico, assim como ao relacionar este tipo de discriminação ao tema da heteronormatividade no contexto organizacional por meio dos conceitos da teoria queer. Em termos práticos, percebem-se exemplos de comentários homofóbicos que não deveriam existir em uma organização que respeite a diversidade.

Palavras-chave: Humor. Discriminação. Heteronormatividade. Homofobia. Diversidade Sexual

\begin{abstract}
This research is part of the studies on sexual diversity in organizations, focusing on the theme of homophobic humor. The aim was to investigate whether homophobic humor is present in the workplace and in what way. In theoretical terms, guided by an interpretativist approach, the article is based on studies on discrimination by means of homophobia and humor, as well as research on heteronormativity in organizations. In order to fulfill the objective, a content analysis was carried out to analyze the interviews carried out with homosexual, bisexual and heterosexual employees of a company. A case study was conducted in a company interviewing employees, regardless their sexual orientation. The interviews were analyzed using Bardin's content analysis method. The presence of the following was observed: frequent homophobic humor; naturalized homophobic humor; homophobic jokes as speech to maintain heteronormativity. There is a scenario in which it is necessary to take actions that promote diversity, especially in relation to the issue of humor, as well as regarding the lack of understanding on the part of workers that jokes containing homophobic humor are linked to oppression. This article contributes to the deepening of national studies on discrimination based on sexual orientation, specifically regarding homophobic humor, and also in terms of relating this type of discrimination to the theme of heteronormativity in the organizational context through the concepts of queer theory.
\end{abstract}

Keywords: Humor. Discrimination. Heteronormativity. Homophobia. Sexual Diversity.

\footnotetext{
* Mestre em Administração de Empresas pelo IAG/PUC-Rio. Tutora EaD do consórcio CEDERJ da Faculdade de Engenharia de Produção do Centro Federal de Educação Tecnológica Celso Suckow da Fonseca (CEFET/RJ) - Rio de Janeiro (RJ), Brasil. E-mail: samira.lep@gmail.com. ORCID: 0000-0003-1305-043X

** Pós-Doutor em Administração pela University of Leicester. Professor do Programa de Pós-graduação em Administração da Universidade Federal do Espírito Santo (PPGAdm/UFES) - Vitória (ES), Brasil. E-mail: eloisio. souza@ufes.br. ORCID: 0000-0002-0775-7757
} 


\section{INTRODUÇÃO}

A percepção da discriminação contra pessoas homossexuais no ambiente de trabalho está associada com atitudes negativas em relação a tais minorias e a uma menor promoção por parte de trabalhadores homossexuais (RAGINS; CORNWELL, 2001). Por outro lado, práticas e políticas organizacionais de suporte não apenas afetam resultados através das percepções de discriminação, como também têm um efeito direto nas intenções de turnover, comprometimento organizacional e comprometimento na carreira. Ou seja, empregados(as) homossexuais em organizações com práticas e políticas de suporte têm atitudes de trabalho mais positivas que empregados de organizações sem tais políticas (RAGINS; CORNWELL, 2001). A discriminação por orientação sexual no trabalho também é refletida nas diferenças salariais entre pessoas heterossexuais e homossexuais como apontam estudos em diversos contextos organizacionais (ALLEGRETTO; ARTHUR, 2001; ARABSHEIBANI; MARIN; WADSWORTH, 2004; BADGETT, 1995; CLAIN; LEPPEL, 2001; LAURENT; MIHOUBI, 2012; KLAWITTER, 2015).

Em relação aos três espaços sociais onde as pessoas desenvolvem sua vida: familiar, social e profissional; é no espaço profissional que a discriminação contra as pessoas homossexuais se torna mais presente (MEDEIROS, 2007). Nos processos judiciais que envolvem discriminações de pessoas homossexuais, 59\% se referem a atos e situações relacionadas ao ambiente de trabalho (POCAHY, 2007), sendo que, independentemente de terem acionado ou não a justiça, $62 \%$ dos homens gays e $59 \%$ de mulheres lésbicas revelam que sofrem discriminação no trabalho (YANG, 1997), sendo que é mais frequente a ocorrência de discriminação informal do que formal contra as pessoas homossexuais, demonstrando que a discriminação no trabalho ainda existe e atualmente tem se manifestado de formas mais sutis (HEBL; GRIFFITH, 2002).

Neste sentido, a existência do humor como forma de discriminação informal homofóbica é recorrente nos resultados de pesquisas em organizações brasileiras que abordam, de uma forma geral, a diversidade por orientação sexual (FERREIRA, 2007; GARCIA; SOUZA, 2010; IRIGARAY; SARAIVA; CARRIERI, 2010; SIQUEIRA; ZAULI-FELLOWS, 2006; ROHM; POMPEU, 2014), assim como também está presente em estudos internacionais (WARD; WINSTANLEY, 2006; WESTWOOD; JOHNSTON, 2011). Para além de homofobia, o tema humor também é utilizado para se compreender outros aspectos relacionados as organizações contemporâneas: humor e sua relação com a produção de estereótipos de pessoas obesas em propagandas (MELO; FARIAS; KOVACS, 2017), dimensões e conceitos sobre humor e seu uso nos estudos organizacionais (DUARTE; DUARTE, 2016; SILVA, 2016); humor como forma de protesto (FURTADO; CARRIERI; BRETAS, 2014) e humor como forma de ironia a atividades laborais específicas (WOOD Jr.; CALDAS, 2005).

Portanto, este artigo objetiva analisar se o humor homofóbico está presente no ambiente de trabalho e de que forma se manifesta, buscando entender sua relação com a homofobia. Neste sentido, o presente estudo almeja contribuir no aprofundamento dos estudos brasileiros acerca da discriminação no trabalho por orientação sexual, especificamente delimitando-se ao tema do humor homofóbico, assim como relacionar este tipo de discriminação ao tema da heteronormatividade no contexto organizacional. Além disso, os conceitos da teoria queer (BUTLER, 1990; COEHN, 1997; LEE; LEARMONTH; HARDING, 
2004; RUMENS; BROOMFIELD, 2014; TYLER; COHEN, 2008; WARNER, 1993) são raramente aplicados nas pesquisas organizacionais brasileiras sobre sexualidade e gênero, muito menos em pesquisas que estudam a relação entre humor e homofobia no contexto do trabalho. Neste sentido, este artigo inova ao utilizar os conceitos queer na análise do humor homofóbico. Para tanto foi realizado um estudo de caso em uma empresa, almejando saber se o humor homofóbico está presente nas relações interpessoais no trabalho, formais ou informais, entre os(as) trabalhadores(as) da companhia e de que forma se manifesta e se relaciona com a lógica heteronormativa. Foram realizadas 12 entrevistas com funcionários(as), independentemente de sua orientação sexual. As entrevistas foram analisadas segundo o método da análise de conteúdo (BARDIN, 1977).

A seguir, como fundamentação teórica, serão apresentados os principais conceitos sobre a discriminação homofóbica e humor nas organizações, assim como sobre a heteronormatividade no contexto organizacional. Em seguida a metodologia utilizada na pesquisa é descrita. Por fim, são analisados os principais resultados encontrados e apresentadas as considerações finais.

\section{DISCRIMINAÇÃO POR HOMOFOBIA E HUMOR NAS ORGANIZAÇÕES}

De acordo com Borrillo (2009) a homofobia é a atitude de hostilidade para com as pessoas homossexuais. Ainda que, segundo o autor, seu primeiro elemento seja a rejeição irracional, ou mesmo o ódio em relação às pessoas homossexuais, a homofobia é uma manifestação arbitrária que consiste em qualificar o outro como "contrário", "inferior" ou "anormal" - sendo este indivíduo (des)qualificado e desta forma colocado em um local fora do universo comum dos humanos. A homofobia é considerada um disturbío severo que produz danos tanto aos homossexuais quanto aos heterossexuais, causando principalmente discriminações e rejeições a homossexuais no campo do trabalho (SERDAHELY; ZIEMBA, 1984).

De acordo com Junqueira (2007) o termo "homofobia" é um neologismo cunhado pelo psicólogo clínico George Weinberg (1972) em 1965, ao vivenciar atos públicos de repúdio direcionados a uma amiga em razão dela ser lésbica. Weinberg (1972) agrupou dois radicais gregos, "semelhante" e "medo", para definir sentimentos negativos em relação aos homossexuais. Ainda, segundo Junqueira (2007), o termo costuma ser empregado em referência a conjuntos de emoções negativas (tais como aversão, desprezo, ódio, desconfiança, desconforto ou medo) em relação a pessoas homossexuais. Tais emoções, segundo o autor, seriam a tradução em determinados casos do receio inconsciente de a própria pessoa homofóbica ser homossexual (ou de que os outros pensem que ela seja). Herek (1991) afirma que a hostilidade para com pessoas homossexuais tem sido denominada de diversas formas: homofobia, heterossexismo, homossexofobia, homossexismo, homonegativismo e anti-homossexualidade; sendo homofobia o termo mais comumente usado na literatura. Contudo, independentemente da nomenclatura utilizada, o preconceito para com os homossexuais é uma resposta a um medo daquilo que se apresenta como diferente quanto tem-se como referência o modelo heterossexual; medo que estabelece e manifesta o preconceito direcionado a homossexuais, fazendo com que estes sejam vistos como uma aberração. As pessoas, que manifestam tal preconceito, não veem que, na realidade, essa 
visão é um reflexo de valores culturais social e historicamente construídos (HEREK, 1991), contribuindo para que, dentre todas as formas de discriminação, a homofobia seja a menos estudada e discutida (RIOS, 2007).

Existem diferentes formas de discriminação, sendo classificada em formal/direta ou informal/indireta (COSTA, 2007; HEBL et al., 2002; LYONS et al., 2005). A discriminação formal/direta manifesta-se nos normativos e procedimentos formais da organização, seja pela ação ou pela omissão de normas e procedimentos que promovam justiça social e igualdade de tratamento entre diferentes orientações sexuais. A discriminação informal/indireta ocorre por meio de comentários inadequados, humilhações, ridicularizações e piadas manifestas no dia a dia nas interações sociais entre pessoas, sendo que a discriminação informal afeta o ajustamento e satisfação no trabalho de empregados gays, bissexuais e lésbicas (LYONS et al., 2005).

Garcia e Souza (2010) apresentam relatos de homens homossexuais funcionários de três bancos (dois públicos e outro privado) que descrevem como o preconceito por orientação sexual, em tais culturas, funciona como barreira para a ascensão profissional. As piadas que retratam os homossexuais de forma caricata e pejorativa foram relatadas como 0 fator causador de maior incômodo dentre os homossexuais entrevistados em seus trabalhos. Os autores verificaram que a homofobia presente nos bancos estudados se reflete nas normas da empresa, ou a ausência delas. A discriminação direta existe na falta de clareza das normas que regularizam a extensão de plano de saúde para o companheiro do funcionário homossexual, assim como pela não extensão de outros benefícios aos casais homossexuais, que são concedidos aos heteros.

A homofobia nas empresas brasileiras, sob a forma do humor, também é relatada no trabalho de Irigaray, Saraiva e Carrieri (2010). Segundo a pesquisa, o humor (comicidade, ironia, piadas, anedota) atua como instrumento de discriminação dos homens gays e das mulheres lésbicas no ambiente de trabalho, naturalizando a homofobia e desrespeitando os indivíduos homossexuais nas organizações.

Ward e Winstanley (2006) estudaram uma organização do corpo de bombeiros do Reino Unido objetivando analisar como a cultura organizacional impacta as minorias sexuais. A questão central do artigo é a como os bombeiros usam a brincadeira e a zombaria para testar novos recrutas. O uniforme e o alarme de fogo foram os exemplos de sinais e símbolos encontrados na pesquisa. 0 uniforme simboliza o fato de que o serviço é semi-disciplinado, as sirenes representam o aspecto da resposta à emergência do serviço. 0 alarme simboliza a diferença entre as duas áreas de trabalho: uma na qual os bombeiros estão esperando que algo ocorra antes de tocar e o outro quando o trabalho ocorre de fato (quando toca o alarme há o incidente), sendo que é no primeiro momento que os bombeiros gays e bombeiras lésbicas sentem-se vulneráveis a exclusão das atividades sociais e de lazer com os outros membros, bem como vítimas de piadas sarcásticas e depreciativas (WARD; WINSTANLEY, 2006).

O humor também foi estudado por Westwood e Johnston (2011) e Tyler e Cohen (2008). Estes autores escolheram analisar o programa de comédia "The office", mencionando que o programa pode ser visto como uma paródia da cultura do management moderna suportada pela heteronormatividade masculina. Westwood e Johnston (2011) afirmam que mulheres, homens gays e pessoas negras são continuamente ridicularizadas e categorizadas 
pelo programa, concluindo em sua pesquisa que o humor possui uma dinâmica dualista: é resistivo, subversivo, mas ao mesmo tempo tem uma dimensão de manutenção do sistema e dos efeitos de ordem. Tyler e Cohen (2008) acrescentam que o conteúdo cômico do programa demonstra que o desejo por reconhecimento suporta a performance e a gestão de gênero nas organizações de acordo com os termos da matriz heterossexual. Portanto, os autores demonstram que existe uma relação entre humor, homofobia, matriz heterossexual e heteronormatividade. Conceitos que serão abordados no próximo tópico deste artigo.

\section{HETERONORMATIVIDADE NAS ORGANIZAÇÕES}

O que se denomina de matriz heterossexual são as práticas regulatórias de normas de gênero (BUTLER, 1990). Neste sentido, a "[...] heterossexualização do desejo requer e institui a produção de oposições discretas e assimétricas entre 'feminino' e 'masculino'" (BUTLER, 1990, p. 24) [tradução nossa]. Segundo a autora, para produzir um efeito de unidade interna e coerência de homens e mulheres, a matriz heterossexual busca estabelecer ao mesmo tempo uma heterossexualidade estável e oposicional, estabelecendo uma inteligibilidade de gênero que visa produzir identidades e verdades por meio de normas que limitam as possibilidades de existência dentro de um sistema oposicional binário de gênero. Tal sistema pressupõe "[...] não somente uma relação casual entre sexo, gênero e desejo, mas sugere também que desejo reflete ou expressa gênero e que gênero reflete ou expressa desejo" (BUTLER, 1990, p. 31) [tradução nossa]. Assim, a "[...] instituição de uma heterossexualidade compulsória e naturalizada requer e regula gênero como sendo uma relação binária na qual o masculino é diferenciado do feminino, e esta diferenciação é realizada através das práticas do desejo heterossexual" (BUTLER, 1990, p. 31) [tradução nossa], produzindo uma coerência e determinismo pelos quais sexo determina gênero e, por usa vez, gênero determina sexo. Entretanto, não se pode considerar a matriz heterossexual como uma estrutura fixa e determinista, pois ela traz consigo possibilidades de resistência que rompem com a ordem normativa estabelecida por elas.

A matriz heterossexual produz uma lógica heteronormativa. Neste sentido heteronormatividade são as práticas e instituições localizadas que legitimam e privilegiam a heterossexualidade e heterossexuais como sendo naturais e fundamentais (COHEN, 1997), ou seja, como sendo o normal dentro da sociedade. Assim, a heteronormatividade estabelece que expressões de gênero e sexualidade são consideradas normais e quais não o são, constituindo não somente os heterossexuais, mas também os próprios homossexuais como sujeitos anormais e falhos (LEE; LEARMONTH; HARDING, 2008; WARNER 1993), pois para que heterossexuais possam adquirir inteligibilidade é necessário que sejam comparados e ligados a homossexuais, criando uma hierarquia social entre eles, demonstrando que a heteronormatividade regula e controla tanto heterossexuais quanto homossexuais (LEE; LEARMONTH; HARDING, 2008). Assim, os pressupostos heteronormativos estão ligados com a institucionalização da heterossexualidade e também moldam a forma de ser e vir a ser heterossexual, assim como moldam a forma de ser das sexualidades alternativas (JACKSON, 2006).

Existe relação entre homofobia e heteronormatividade, pois para que a homofobia exista deve ser estabelecido uma distinção que caracterize a homossexualidade como ilegí- 
tima em relação ao modelo heteronormativo e, portanto, passe a ser considerada como um perigo a ser combatido (RIOS, 2007), pois produz instabilidade ao modelo binário da matriz heterossexual ao romper com a relação casual e determinística em que desejo reflete e expressa gênero e que gênero reflete e expressa desejo (BUTLER, 1990). O homem afeminado e a mulher masculinizada colocam em risco o binarismo sexual exatamente por terem traços biológicos de um homem e de uma mulher, mas comportamentos culturalmente definidos como pertencentes ao feminino e ao masculino. Eles incomodam porque, a todo o tempo, estão navegando e quebrando as fronteiras culturalmente estabelecidas entre o masculino e o feminino, colocando em risco o modelo binário heteronormativo (LOURO, 2004).

Em homens heterossexuais que possuem crenças precárias de sua própria masculinidade o humor sexista e homofóbico atua como uma forma de autoafirmação de sua masculinidade. Eles demonstram divertimento ao realizar piadas sexistas e homofóbicas exatamente porque tais piadas atuam como um mecanismo estratégico de defesa de eventuais ameaças as suas próprias masculinidades (O'CONNOR; FORD; BANOS, 2017). Portanto, o humor atua como um processo que pode tanto romper a ordem hegemônica de gênero, quanto mantê-la (WEAVER; MORA; MORGAN, 2016). Além disso, homens são vistos como mais tendenciosos a praticarem atos de humor no dia a dia do que mulheres (MICKES et al., 2012).

Apesar de identidades de gênero e de orientação sexual não serem a mesma coisa e não terem uma relação determinística entre elas, a matriz heterossexual busca produzir, por meio de sua inteligibilidade, a naturalização de um determinismo entre gênero e sexualidade e vice-versa. Exatamente pelo fato de gênero não determinar sexualidade e sexualidade não determinar gênero (BUTLER, 1990) surgem expressões de gênero e desejo que não seguem a lógica da matriz, como a homossexualidade. Assim, a homossexualidade coloca em cheque o modelo binário da matriz heterossexual ao mesclar os componentes culturais do masculino e feminino que a matriz insiste em manter separados (TREVISAN, 1997), fazendo com que a homossexualidade seja vista como 0 afronto mais radical e incomodo às instituições e valores da sociedade (RIOS, 2007).

A heteronormatividade está ligada à construção do que é tido como masculino e feminino no espaço organizacional. A análise visual de imagens e textos de Panayiotou (2010) sobre como a masculinidade é construída no ambiente de trabalho, em diversos filmes populares, também revela a presença da heteronormatividade na construção dos personagens gestores. Os resultados de sua análise revelam que a heterossexualidade é um elemento constante presente em tais construções do masculino nos filmes. Os gestores são construídos de formas estereotipadas nos filmes populares: são homens heterossexuais, que mostram seu poder financeiro mediante os objetos que compram, roupas, carros e mulheres (PANAYIOTOU, 2010). Os gestores nos filmes da referida pesquisa gostam de controlar as pessoas que estão em torno deles e seus próprios corpos, satisfazem sua ganância por meio do poder e sexo, trabalham muitas horas, não possuem outra casa se não o trabalho e desvalorizam a educação formal.

A heteronormatividade está fundamentada em falsos pressupostos de naturalização das práticas heterossexuais e no caráter tido como desviante de outras práticas (LIONÇO; DINIZ, 2008). Segundo os autores, a heteronormatividade se sustenta em grande parte na naturalização da família heterossexual e patriarcal. A suposta neutralidade da 
heterossexualidade como fundamento do laço afetivo e sexual restringe a possibilidade do reconhecimento de famílias constituídas por parceiros do mesmo sexo, assim como inferioriza o envolvimento amoroso entre pessoas do mesmo sexo ao status do não legítimo e estranho (LIONÇO; DINIZ, 2008). A heteronormatividade define não apenas uma prática sexual normativa, mas também um modo de vida "normal" (JACKSON, 2006).

Embora algumas organizações possam ser tidas como "gay-friendly" nem sempre representam um modelo de organização livre da heteronormatividade. Assim, Rumens e Broomfield (2014) entrevistaram homens gays que trabalham em espaços artísticos performáticos (como teatro, filme, teatro musical, circo, TV) por serem tais lugares tidos como gay-friendly. Os autores encontraram que a sexualidade dos homens gays é homogeneizada e fixa dentro de um molde heteronormativo, o qual lança dúvidas sobre a capacidade dos artistas homossexuais de atuarem em partes masculinas nas performances, requerendo performances de gênero diferentes. As concepções heteronormativas de sexualidade funcionam de forma a impedir os artistas gays de conseguirem trabalho (nas artes cênicas, por exemplo, pelo estereótipo da feminilidade). Ainda que as organizações artísticas possam ser consideradas como gay-friendly, Rumens e Broomfield (2014) perceberam que os contextos de trabalho de seus entrevistados pareceram ser intensamente heteronormativos.

\section{PROCEDIMENTOS METODOLÓGICOS}

A presente pesquisa configura-se como um estudo de caso (YIN, 2010) realizada em uma empresa do setor de petróleo com 12 pessoas entrevistadas por meio de um roteiro de entrevista semiestruturado com perguntas abertas. Inicialmente, já que nenhum dos autores trabalha na empresa do estudo de caso, não foi fácil ter acesso aos funcionários sem ter vínculo com a organização, ainda mais pelo fato de a pesquisa ter como tema o estudo da homofobia. Assim, para tornar a pesquisa exequível, algumas pessoas entrevistadas inicialmente foram selecionadas de acordo com contatos do círculo social da autora e, a partir destes contatados, foram indicadas outras pessoas a serem entrevistadas - como orienta a técnica snowball (bola de neve). Snowball sampling é um método largamente utilizado para acessar populações específicas, sendo que a técnica de bola de neve é frequentemente usada quando a população sob investigação é formada por grupos considerados minoritários ou porque existe grande sensibilidade ao tema abordado pela pesquisa, como homossexuais que não se enquadram na norma hegemônica heterossexual (BROWNE, 2005), sendo indicada para estudos relacionados a comportamentos sociais que são considerados desviantes (BIERNARCK; WALDORF, 2016).

Consideramos 12 pessoas o ponto de saturação, já que os relatos de piadas homofóbicas começaram a se repetir nos últimos entrevistados, assim como exemplos de tal humor. Tais entrevistados foram escolhidos independente da orientação sexual. Ainda que a maior parte das pesquisas organizacionais sobre o tema da diversidade por orientação sexual no Brasil sejam restritas a pessoas LGBTs, desejou-se incluir aqui, também, os funcionários(as) heterossexuais por acreditar-se que não apenas entrevistados(as) LGBTs possam relatar discursos de discriminação homofóbica e de heteronormatividade como também os heterossexuais, pois tanto homossexuais quanto heterossexuais são sujeitados à matriz heterossexual e às normas heteronormativas para poderem existir como sujeitos 
de determinado gênero e orientação sexual. A não delimitação por uma orientação sexual específica ocorreu, também, por levar em conta relatos dos(as) funcionários(as) sobre suas observações de seu ambiente de trabalho - de onde pode emergir comentários homofóbicos ou heteronormativos com outras pessoas como colegas de trabalho ou trabalhadores do mesmo setor.

Foi acordado com as pessoas entrevistadas que o nome da empresa não seria divulgado, bem como a identidade delas. Assim, foi utilizado um código para se referir a cada pessoa entrevistada na análise de acordo com a ordem cronológica em que ocorreram as entrevistas (E1 para o primeiro entrevistado, E2 o segundo e assim por diante até o E12). Foi perguntado como a pessoa se declara em termos de gênero e orientação sexual, nível do cargo e tempo de empresa, antes de entrar nas perguntas sobre as relações interpessoais e orientação sexual no ambiente de trabalho. 0 instrumento de coleta de dados, elaborado com base em Yin (2010) e na literatura sobre o tema, também contou com perguntas sobre a equipe de trabalho, os relacionamentos com os colegas, se a pessoa já presenciou a discriminação por orientação sexual (e o que foi feito pela empresa, em caso afirmativo), se a pessoa entrevistada ouve piadas, ironias ou falas depreciativas sobre orientação sexual de funcionários assumidos ou percebidos como LGBTs. Foram solicitados exemplos, quando ocorriam, e perguntado se isso era fora da empresa, em eventos informais.

Em relação às características de gênero e orientação sexual, foi entrevistado um homem bissexual (E1), quatro homens homossexuais (E4; E7; E10; E11), quatro homens heterossexuais (E2; E6; E8; E9), três mulheres heterossexuais (E3; E5; E12). Apenas um dos entrevistados considerou a possibilidade de indicar uma funcionária lésbica para entrevista, porém não obtivemos sucesso nesta empreitada. Além dele, não obtivemos notícias nem indicações de outras possíveis entrevistadas homo ou bissexuais. Em termos de cargo, foi entrevistado um ex-estagiário (E1), três funcionários que ocupam cargo de nível técnico (E4; E10; E12) e oito funcionários que ocupam cargo de nível superior (E2; E3; E5; E6; E7; E8; E9; E11). Todos pertencem a áreas diferentes da empresa, ou seja, foram entrevistadas pessoas de 12 áreas distintas. A idade média dos entrevistados é de 32,58 anos. 0 tempo de empresa variou de um a nove anos, sendo o tempo médio de trabalho na empresa de 5,58 anos.

As entrevistas foram gravadas e depois transcritas. A seguir foram selecionados os fragmentos mais relevantes que possuíssem conexão com os conceitos de humor homofóbico e heteronormatividade. Para a análise dos dados, escolheu-se utilizar o método da análise de conteúdo. (BARDIN, 1977). Este método pode ser definido como "[...] um conjunto de técnicas de análise das comunicações, que utiliza procedimentos sistemáticos e objetivos de descrição do conteúdo das mensagens" (BARDIN, 1977, p.38). A intenção do método é "[...] a inferência de conhecimentos relativos às condições de produção (ou, eventualmente, de recepção), inferência esta que recorre a indicadores (quantitativos ou não)" (BARDIN, 1977, p. 38).

Consideramos o referido método adequado, uma vez que, segundo Mozzato e Grzybovski (2011), a análise de conteúdo pode ajudar pesquisadores que buscam desenvolver estudos no campo de administração segundo uma abordagem analítica crítica e reflexiva - como é o caso do tema desta pesquisa. Os fragmentos foram agrupados em três grupos categóricos dentro dos quais foram analisados, a saber: humor homofóbico frequente; hu- 
mor homofóbico naturalizado; piadas homofóbicas para manter a heteronormatividade. Tais categorias foram elaboradas ex-post, ou seja, a partir da pesquisa de campo e após a leitura das transcrições das entrevistas.

\section{ANÁLISE DOS RESULTADOS}

Conforme descrito na metodologia, foram criadas três categorias temáticas no processo de análise dos dados produzidos. As categorias criadas e a descrição constam do Quadro 1. Os próximos tópicos da análise seguem a ordem das categorias apresentadas no quadro.

Quadro 1 - Categorias de análise de conteúdo da discriminação homofóbica mascarada pelo humor e a heteronormatividade no contexto organizacional

\begin{tabular}{|c|c|c|c|}
\hline Categoria & Descrição & Subcategorias & Exemplos \\
\hline \multirow{2}{*}{$\begin{array}{l}\text { (1) Humor } \\
\text { homofóbico } \\
\text { frequente }\end{array}$} & \multirow{2}{*}{$\begin{array}{l}\text { Revela a alta frequência com que } \\
\text { as pessoas escutam piadas de } \\
\text { humor homofóbico no trabalho. }\end{array}$} & Alta frequência & $\begin{array}{l}\text { "sempre tem"; "isso } \\
\text { rola direto, 'deixa de } \\
\text { viadagem' no ambiente } \\
\text { corporativo". }\end{array}$ \\
\hline & & Homofobia diária & $\begin{array}{l}\text { "As mesmas piadas da } \\
\text { homofobia cotidiana". }\end{array}$ \\
\hline \multirow{3}{*}{$\begin{array}{l}\text { (2) Humor } \\
\text { homofóbico } \\
\text { naturalizado }\end{array}$} & \multirow{3}{*}{$\begin{array}{l}\text { Apresenta a naturalização do } \\
\text { humor homofóbico, seja por } \\
\text { discursos atribuídos a cultura } \\
\text { brasileira, à infantilidade ou à } \\
\text { uma discriminação genérica, } \\
\text { porém sempre minimizando o real } \\
\text { peso da discriminação. }\end{array}$} & $\begin{array}{l}\text { O discurso do homofóbico } \\
\text { politicamente correto }\end{array}$ & $\begin{array}{l}\text { "acho que a gente anda } \\
\text { muito politicamente } \\
\text { correto [...], mas eu } \\
\text { morro de rir de piadas". }\end{array}$ \\
\hline & & $\begin{array}{l}\text { Naturalização ao atribuir à } \\
\text { cultura brasileira }\end{array}$ & $\begin{array}{l}\text { "Essa discriminação } \\
\text { brasileira comum do dia } \\
\text { a dia". }\end{array}$ \\
\hline & & $\begin{array}{l}\text { Naturalização ao associar } \\
\text { à outras causas que não o } \\
\text { preconceito }\end{array}$ & $\begin{array}{l}\text { "genérica, não voltada a } \\
\text { uma pessoa". "infantilida- } \\
\text { de. Mais do que qualquer } \\
\text { outra coisa" }\end{array}$ \\
\hline \multirow{6}{*}{$\begin{array}{c}\text { (3) Piadas } \\
\text { homofóbicas } \\
\text { para manter a } \\
\text { hetero-normati- } \\
\text { vidade }\end{array}$} & \multirow{6}{*}{$\begin{array}{l}\text { Discursos homofóbicos e } \\
\text { heteronormativos baseados } \\
\text { na construção do masculino, } \\
\text { na misoginia e associação da } \\
\text { homossexualidade ao feminino. } \\
\text { Necessidade da autoafirmação } \\
\text { da masculinidade por meio da } \\
\text { opressão; a associação da homos- } \\
\text { sexualidade ao valor negativo. }\end{array}$} & $\begin{array}{l}\text { Criar oportunidades para } \\
\text { fazer piada }\end{array}$ & $\begin{array}{l}\text { "isso é bom pra você } \\
\text { pode colocar seu namo- } \\
\text { rado". }\end{array}$ \\
\hline & & Associação ao feminino & "Vai princesa". \\
\hline & & $\begin{array}{l}\text { Autoafirmação por meio do } \\
\text { humor homofóbico }\end{array}$ & $\begin{array}{l}\text { "Aquele cara que tem } \\
\text { que se afirmar como } \\
\text { maacho". }\end{array}$ \\
\hline & & \multirow[b]{2}{*}{ Machismo e homofobia } & $\begin{array}{l}\text { "quando você tem muito } \\
\text { homem junto sempre } \\
\text { tem"; }\end{array}$ \\
\hline & & & $\begin{array}{l}\text { "aí viadinho, não aguenta } \\
\text { beber mais não"; "tá sain- } \\
\text { do porque o macho não } \\
\text { deixa ficar até tarde?". }\end{array}$ \\
\hline & & $\begin{array}{l}\text { Atribuição do valor negati- } \\
\text { vo ao homossexual }\end{array}$ & $\begin{array}{l}\text { "Ah, isso aí é viadagem } \\
\text { [...] Alguma coisa } \\
\text { negativa". }\end{array}$ \\
\hline
\end{tabular}

Fonte: Elaboração dos autores. 


\subsection{HUMOR HOMOFÓBICO FREQUENTE}

A heteronormatividade produz uma inteligibilidade sobre tanto o que é ser heterossexual quanto o que é ser homossexual, definindo fronteiras e muros entre estas identidades. (BUTLER, 1990; COHEN, 1997). Ao estabelecer uma relação hierárquica e oposicional entre tais identidades faz com que aquilo que é considerado como o anormal nesta relação seja o tempo todo repetido, recitado e lembrado nas relações sociais diárias, exatamente por não se apresentar como o natural e normal e, assim sendo, é o que torna-se visível e alvo de controle e preconceitos. Por isso em diversos relatos, as pessoas entrevistadas - independentemente da orientação sexual - relataram que as piadas em relação à homossexuais são frequentes e manifestam-se de uma forma sútil como pode ser visto a seguir:

E4: É claro, uma ou outra piadinha fora de hora, sempre soltam, e aí você... Hoje mesmo aconteceu: Aí, "E4"! Oi! Você vai na parada gay, fulano de tal? É numa favela aqui no Rio de Janeiro, sei lá onde que é. Eu falei: 'Vai esperando sentada, que eu vou'. Mas eu vou, claro, não tem problemas, não. Mas a notícia soa como piada, também.

As piadas são vistas como constantes para E4, qualificando sua frequência com o advérbio de tempo "sempre". De fato, piadas sobre homossexuais são tão presentes no ambiente de trabalho e sua frequência tão constante que no próprio dia da entrevista ("hoje mesmo") E4 possuía um exemplo de piada contra homossexuais (no caso sobre ele mesmo) para citar. Um dos colegas de trabalho de E4, que é assumido, usa a condição social da favela como forma de ironizar e discriminar homossexuais, relacionando favela a homossexuais, buscando com isso associar preconceitos relacionados a aspectos de classes sociais consideradas inferiores como definidores dos homossexuais, não considerando que esta visão de inferioridade direcionada a homossexuais, de fato, é fruto de valores culturais e sociais. (HEREK, 1991) Quando perguntado se em eventos informais havia a presença de piadas, o que caracteriza discriminação informal/indireta (COSTA, 2007; HEBL et al., 2002; LYONS et al., 2005), E8 responde de forma afirmativa que "Ah, sempre tem [...] Ah, esse tipo de brincadeira assim: "ah, é frescura, é viadagem, não sei o que... Não sei, nada demais".

Aliás, a naturalização de piadas sobre homossexuais adjetivadas pelo termo "nada demais" é frequente nos discursos dos entrevistados. A constante presença de tais piadas e a adjetivação como sendo "nada demais", manifesta uma tentativa de considerar tais piadas como não sendo preconceituosas ou discriminatórias, procurando mascarar visões preconceituosas (WARD; WINSTANLEY, 2006) com a utilização da expressão "nada demais". Os enunciados manifestos pelos entrevistados demonstram o papel do discurso na construção da cultura organizacional homofóbica, bem como o impacto deste discurso em minorias sexuais nos contextos laborais, explicitando porque homossexuais sintam-se muito mais incomodados com a presença de discriminações informais/indiretas no ambiente de trabalho do que com as discriminações formais/diretas (GARCIA; SOUZA, 2010).

E2: As piadas? As mesmas piadas que tem no ambiente de trabalho tem na festa. Aí não tem jeito. A única vez que já vi - mudando a pergunta, se 
eu já vi alguém levar o parceiro para a festa foi na do sindicato. Foi o E10 que levou o companheiro dele, foi uma festa quando o sindicato ganhou, quando a gente ganhou o sindicato... Na verdade, de novo, aí teve a festa aí o E10 foi com o companheiro dele. Mas era do sindicato, não era da empresa mesmo. Da empresa mesmo eu nunca vi ninguém levar o companheiro. Mas piadas homofóbicas com certeza. As mesmas piadas da homofobia cotidiana. Também aparecem nas festas. Porque fica naquela questão (imita a voz dos outros): "não tenho nada contra, mas se o meu filho fosse eu não ia gostar". Mas aí faz as piadas homofóbicas. Não é uma coisa tão declarada assim quanto outros casos, mas é o que mais acontece na sociedade.

O enunciado acima de $\mathrm{E} 2$, heterossexual, reforça ainda mais a presença constante em todos os espaços corporativos, sejam eles sindicais ou laborais, das discriminações informais por meio de comentários inadequados e piadas manifestas nas diversas interações sociais ocorridas nestes espaços (COSTA, 2007; HEBL et al., 2002; LYONS et al., 2005). 0 entrevistado 2 percebe um paralelismo entre as piadas do dia a dia no trabalho com as dos eventos informais. Como a pessoa não tem nada contra se não gostaria do próprio filho homossexual? E é esta mesma pessoa que faz as piadas discriminatórias, sendo esta a crítica expressa no discurso do entrevistado a estes sujeitos. Mesmo os entrevistados homossexuais percebem a presença de piadas entre heterossexuais em eventos informais com base na homossexualidade e a discriminação informal contida nelas.

E11: Sim, sim. Acho que é ainda mais frequente (piada em evento informal). Que as pessoas se desamarram um pouco, estão fora da [empresa]. Então é mais frequente fazer essa piadinha em ambientes mais informais. [...] Ah, se o cara não aguenta tomar mais um chopp: "e aí viadinho, não aguenta beber mais, não?". Ou vai sair cedo: "aí, tá saindo porque o macho não deixa ficar até tarde?". São esses tipos de piadinha que eu acho que são muito comuns em qualquer ambiente hetero. 0 hetero tem essa fixação gay, né? De fazer piadinha e menosprezar o outro.

E11 acredita que há uma maior frequência de piadas que envolvam a questão da orientação sexual em eventos informais. Se a pessoa não quer tomar mais um chopp a palavra discriminadora é ser chamada de "viado". Se quer sair mais cedo, associa-se ao controle de um outro homem, sofrendo retaliações verbais homofóbicas. 0 entrevistado 11 percebe o menosprezo que é dado aos homossexuais por meio destes discursos, acreditando haver uma "fixação gay". Uma das explicações para esta fixação gay é que homens heterossexuais utilizam o humor homofóbico como forma de autoafirmação de sua masculinidade, uma estratégia de defesa da precariedade de sua própria masculidade (O'CONNOR; FORD; BANOS, 2017). Além disso, a matriz heterossexual legitima e privilegia a heterossexualidade, constituindo o heterossexual como normal e natural, considerando todos os sujeitos que não seguem as normas estabelecidas pela matriz como inferiores, falhos e anormais (COHEN, 1997; LEE; LEARMONTH; HARDING, 2008; WARNER, 1993). Tal fato também pode ser constatado ao se atribuir algumas atividades laborais como não naturais a homens gays, conforme E6 declara abaixo. 
E6: Mas isso rola direto, "deixa de viadagem" no ambiente corporativo [...] É, mas o que mais tem é isso, coitado de um gay que vá fazer engenharia porque deve ser insuportável. Com os amigos e eu já ouvi muito, deixa de bichisse, parece uma bichinha, sabe?

0 relato do entrevistado 6 , heterossexual, mostra a inteligibilidade construída pela matriz heterossexual em relação a quais atividades laborais seriam mais adequadas ou não para homossexuais, considerando que engenharia não é uma profissão adequada para um gay, possivelmente por considerar engenharia uma atividade extremamente masculina e associar gays a feminilidade. Além disso, a presença constante de comentários homofóbicos "deixa de viadagem" e "deixa de bichisse", gerando um preconceito a determinados comportamentos e atitudes como se fossem essencialmente gay (HEREK, 1991), construindo uma inteligibilidade caricata tanto de homens gays quanto destas atitudes e comportamentos (GARCIA; SOUZA, 2010).

\subsection{HUMOR HOMOFÓBICO NATURALIZADO}

A presença constante do humor homofóbico no ambiente de trabalho, relatado no tópico anterior deste artigo, já é um indicativo de quão naturalizado este tipo de humor encontra-se no ambiente de trabalho. Estar naturalizado significa dizer que o humor homofóbico é praticado de forma natural, ou seja, sua prática nem é problematizada, questionada ou percebida como homofóbica, incorporando-se automaticamente nas interações ocorridas no trabalho (SERDAHELY; ZIEMBA, 1984). Diversos entrevistados percebem o humor contra as homossexuais como algo natural ou não problematizável:

E6: $E$ acho que a gente anda muito politicamente correto [...] e acho um saco isso, e eu não tenho preconceito absolutamente nenhum. Nenhum. Sei lá, negro, homossexual, judeu, português. Só opcionalmente desses que eu consigo pensar, tem alguns preconceitos que eu nem sei se são preconceitos. Mas eu acho que tem umas piadas que são de muito mau gosto, independente de qual tipo, tem alguns que, não tem nem preconceito, imagina com piadas grotescas sai palavrão, mas eu morro de rir de piadas, às vezes, de português e negro, judeu, de gay e cara, sei lá, eu acho que, tem uma farsa de politicamente correta que me incomoda.

O humor atua como um dispositivo discriminador que naturaliza a homofobia nas práticas organizacionais, fazendo com que por meio desta naturalização os danos, os desrespeitos e os traumas psicológicos que tais piadas produzem nos homossexuais não sejam percebidos pelos seus praticantes (IRIGARAY; SARAIVA; CARRIERI, 2010). O entrevistado 6 , heterossexual, considera o movimento contrário as piadas como algo "politicamente correto", sendo o politicamente correto que o incomoda e não as piadas homofóbicas em si. De fato, ele não percebe a verdade, o verdadeiro incômodo que essas piadas causam a quem é vítima delas. Esta naturalização das piadas homofóbicas ocorre exatamente pela naturalização do heterossexual como sendo o normal e o padrão a ser seguido por todos na sociedade. Dentro da lógica binária produzida pela matriz heterossexual um polo será valorizado enquanto que o outro é desvalorizado, ou seja, para que o heterossexual seja esta- 
belecido como o normal é necessário desqualificar e inferiorizar outras formas de orientação sexual, estabelecendo-se uma hierarquia entre elas (BUTLER, 1990). Nesta relação, o que é inferiorizado adquire uma constante visibilidade, enquanto que a sexualidade considerada normal obtém uma invisibilidade por ser naturalizada como o normal.

Dentro da lógica heteronormativa o heterossexual é naturalizado, não problematizado ou questionado pela sociedade, mas considerado o normal e o padrão a ser seguido por todos. De forma até mesmo antagônica, sendo o homossexual socialmente construído como anormal, defeituoso e falho, faz com que a homossexualidade seja visível, vigiada e questionada, e assim permite-se que seja objeto de comentários maliciosos. É exatamente esta visibilidade constante e a percepção de anormalidade que a homossexualidade traz consigo, dentro da lógica heteronormativa, que estabelece que piadas contra homossexuais sejam naturalizadas, pois piadas homofóbicas também funcionam como um dispositivo de controle que visa coibir pessoas de se identifiquem com uma identidade homossexual por terem medo de serem vítimas destas piadas. Enfim, a naturalização das piadas homofóbicas atua como um dispositivo de vigilância e controle social. Assim, o humor serve para manutenção do sistema e dos efeitos da ordem heteronormativa (TYLER; COHEN, 2008; WEAVER; MORA; MORGAN, 2016; WESTWOOD; JOHNSTON, 2011). Outra explicação para a naturalização das piadas homofóbicas no ambiente de trabalho está presente no discurso dos entrevistados. Esta explicação está fundamentada em aspectos culturais do brasileiro, conforme E9 e E11 relatam a seguir:

E9: Sempre tem. Sempre tem. Isso aí é aquela história: eu acho que é até cultural do brasileiro, um negócio muito ruim isso. Quando acontece alguma coisa, vem uma frase né: "ah, isso é coisa de viado". Umas coisas bem chulas mesmo, né? Pontos de vista ridículos das pessoas em relação a isso. Existem piadas disso, tem gente que adora, que ri... [...]. Tem até aquelas brincadeiras mais bobas, homem faz muito essa brincadeira de chamar, virar pra o outro: 'ah, você é isso, você é aquilo'. Mas, novamente: infantilidade. Mais do que qualquer outra coisa.

E11: Já [viu discriminação]. Essa discriminação brasileira comum do dia a dia. De, passa um gay mais afeminado e aí fazem uma piadinha. Ou até entre dois heteros e aí xinga de viado. Que é algo muito comum, não de cargo gerencial para subalterno, entre pares mesmo. Esse preconceito que é muito tradicional no Brasil. Mas de gerente pra subordinado não.

O entrevistado E9 para justificar a naturalização de piadas homofóbicas no ambiente de trabalho apresenta o argumento de que fazer piadas contra homossexuais é uma característica "cultural do brasileiro", apesar de reconhecer como algo negativo tal naturalização, tentando minimizar esta negatividade ao atribuir a esta prática naturalizada na cultura brasileira como sendo uma infantilidade. O humor como forma de discriminação naturalizada na cultura brasileira também é percebida por E11, homossexual, ao afirmar que ela é uma "discriminação brasileira comum do dia a dia" e ainda complementa tal afirmação ao declarar que "Esse preconceito que é muito tradicional no Brasil". 


\subsection{PIADAS HOMOFÓBICAS PARA MANTER A HETERONORMATIVIDADE}

Além da naturalização das piadas homofóbicas como dispositivo de vigilância para se manter a heteronormatividade, se observou nos discursos dos entrevistados outras formas de manutenção da heteronormatividade com o objetivo de manter e preservar a inteligibilidade entre gênero e sexualidade produzida pela matriz heterossexual (BUTLER, 1990). Gênero não é o mesmo que sexualidade e ambos são construções sócio-históricas ao invés de pertencerem a ordem da natureza. Além disso, gênero não determina a sexualidade e vice-versa, pois nem todos os homens que produzem e consomem o feminino são homossexuais e nem todas as mulheres que produzem e consomem o masculino são lésbicas. Apesar destas considerações, os entrevistados em seus discursos manifestam constantemente que gênero é determinante da sexualidade.

E12: Alguma coisa negativa assim. Por exemplo, algum comentário pejorativo. Por exemplo, quando algum cara fica comentando a roupa de alguma menina quando ela chega, entendeu? "Ah, você está com uma blusa aí..." Aí sempre tem alguém que aparece: "porra, isso pra mim é viadagem. Ficar prestando atenção na roupa dela? Daqui a pouco você está falando do batom, tá pedindo pra pintar a unha". Tem esse comentário também. Ai, tanta coisa. Todo dia tem uma nova. Todo dia. Piadinha, cara? Todo dia tem. Tem o pessoal que brinca um com o outro: "ah, meu amor". [...] É só pra zuar. "Vem cá meu amor. Você e esse negão fortão aí... não sei o que. Todo gostosão e tal. Vou te dar um abraço".

No exemplo da entrevistada 12, heterossexual, usa-se o termo pejorativo "viadagem" para depreciar certos comportamentos considerados femininos, como comentar uma roupa de uma mulher. Pelo simples fato de um homem comentar sobre uma blusa de uma mulher, um batom ou um esmalte ele já é associado como sendo homossexual nas piadas e brincadeiras no trabalho, demonstrando que homens tendem a praticar mais atos de humor do que mulheres (MICKES; WALKER; PARRIS; MANKOFF; CHRISTENFELD, 2012). Se, conforme dito anteriormente, gênero não determina sexualidade, por que E12 considera isso algo determinante, acreditando que feminino não é um atributo pertencente a homens heterossexuais, mas somente a homossexuais? Isto pode ser explicado pela inteligibilidade produzida pela matriz heterossexual, pela qual o sexo de nascimento determina o gênero que por sua vez determina a sexualidade, ou seja, se alguém nasce com pênis é homem (sexo) e por ser homem tem somente o gênero masculino e a sexualidade heterossexual (BUTLER, 1990). Essa relação determinística entre sexo, gênero e sexualidade estabelecida pela matriz heterossexual explica porque os entrevistados acreditam que o gênero masculino determinaria a sexualidade heterossexual, pois a "[...] heterossexualização do desejo requer e institui a produção de oposições discretas e assimétricas entre 'feminino' e 'masculino'" (BUTLER, 1990, p. 24) [tradução nossa]. Tal fato também pode ser observado no enunciado de $\mathrm{E9}$ abaixo.

E9: Tem um colega lá que ele é preconceituoso, ele fala um monte de bobagens. Aquele cara que tem que se afirmar como macho e tal [...] Na hora do almoço eu chego com ele e falo: vamo comer, fulano? Ai ele: "Não! Comer não! Não vai me comer não!" [...]. Outro dia botaram um chocolate lá e 
ele falou: não, chocolate eu não como não! "Com um colega botaram um chocolate num dia e no outro dia botaram um vestido". [...] Ah, momento informal tem muita piada. Momento formal não vai ter [...] Ele fica nervoso quando a gente fala e tal e aí a gente brinca, fica espetando ele porque ele tem uma reação assim completamente absurda, sabe?

No caso do entrevistado 9, heterossexual, seu colega de trabalho tem uma necessidade exagerada de autoafirmar a sua suposta heterossexualidade (que o entrevistado chama de "masculinidade", como se não fosse possível um homem homossexual ser masculino). Novamente o humor atua como um mecanismo de defesa, utilizado quando o sujeito apresenta uma masculinidade precária (O'CONNOR; FORD; BANOS, 2017). O colega de E9 o faz em cima de comentários comuns que qualquer funcionário poderia fazer para outro - como o convite para almoçar - e nos quais ninguém está colocando em cheque sua heterossexualidade. A genereficação do desejo produzida pela matriz heterossexual busca produzir um efeito de unidade interna, estabilidade e coerência de homens e mulheres ao estabelecer uma heterossexualidade binária e oposiconal, pela qual homem não contém feminino e mulher não contém masculino, limitando as possibilidades existenciais dentro deste sistema oposicional que estabelece "[...] não somente uma relação casual entre sexo, gênero e desejo, mas sugere também que desejo reflete ou expressa gênero e que gênero reflete ou expressa desejo" (BUTLER 1990, p. 31) [tradução nossa]. Como os homossexuais são considerados sujeitos falhos e defeituosos pela matriz heterossexual o feminino será atribuído a eles, sendo comum serem tradados como se fossem femininos (princesa).

E3: Direto. Lá, por exemplo, os meninos ficam um zoando o outro, falam que é a sociedade do anel. Mas é tudo na brincadeira [...] Quando vai embora, falam assim: "tchau amor, te espero ali na esquina!", um fala para o outro. "Vai princesa!". Mas não fica falando palavrão. Ali é aquela coisa mais light. E quem brinca são as pessoas descontraídas, eu brinco também [...] Da sociedade do anel são três ou quatro [...]. E o mentor é consultor já antigo da empresa. É bom palhaçadas e brincadeiras, no geral.

Para ocorrer a institucionalização de uma heterossexualidade compulsória é necessário regular gênero como sendo binário pelo qual masculino e feminino são polos opostos e excludentes, diferenciando masculino de feminino (BUTLER, 1990). Portanto, a heteronormatividade não estabelece apenas uma prática sexual normativa, mas também qual é o modo de vida normal (JACKSON, 2006), contribuindo para a existência da homofobia, pois a homofobia existir deve se estabelecer uma distinção que caracterize a homossexualidade como ilegítima e anormal (RIOS, 2007). A homossexualidade coloca em cheque e em risco toda a inteligibilidade de gênero produzido pela matriz heterossexual e por isso deve ser combatida (RIOS, 2007). O combate ocorre nas diversas práticas homofóbicas diárias, como as piadas, pois o homem afeminado e a mulher masculinizada colocam em risco o binarismo da matriz heterossexual, ao romperem fronteiras estabelecidas por ela (LOURO, 2004). Além disso, pela inteligibilidade da matriz heterossexual a relação sexual valorizada e permitida é a reprodutiva heterossexual. Qualquer relação que não possa reproduzir é desvalorizada, como ilustrado a seguir. 
E6: Inclusive, recentemente, acho que foi ano passado, fazem piada disso comigo também, que você pode colocar o parceiro na NF, que é o plano de saúde da [empresa]. Acho que isso é uma formalização dos valores da companhia [...]

Pesquisadora: E a piada que tipo por exemplo?

E6: Ah, "pode colocar o seu aí!", "tá sabendo isso? É bem pra você e tal". Isso todo mundo sacaneia, negócio de ir contando piada ao mesmo tempo, quando rolou isso todo mundo sacaneava. "E aí, tá sabendo, isso é bom pra você pode colocar seu namorado".

Assim, ao saber da existência da extensão de benefícios do plano de saúde para parceiros(as) de casais homossexuais, os colegas de trabalho ridicularizam este fato incluindo o próprio $\mathrm{E} 6$, heterossexual, ao brincar como se ele tivesse um namorado. Ou seja, a única forma de relação afetiva legitima é a reprodutiva estabelecida pela matriz heterossexual. Percebe-se aqui, com base nos diversos fragmentos, que as piadas ligadas à homossexualidade relatadas não têm nada de "inocentes" ou de "brincadeiras". Servem ao propósito de manterem uma cultura organizacional heteronormativa e homofóbica, explicitando que comportamento é julgado adequado (heteronormativo) e qual não é (o associado a homossexualidade).

\section{CONSIDERAÇÕES FINAIS}

Constatou-se, mediante a análise de conteúdo das falas dos(as) funcionários(as) entrevistados(as), a presença do humor homofóbico frequente na empresa em que trabaIham, inclusive em eventos informais - o que foi relatado tanto por pessoas homossexuais quanto heterossexuais. Tais piadas ocorreram tanto com as pessoas entrevistadas quanto com outras pessoas com as quais trabalham.

As falas de humor homofóbico na organização nem sempre foram percebidas por algumas pessoas entrevistadas com a gravidade que possui, pois muitas vezes elas naturalizam a ocorrência desta forma de humor ao não o associarem a um ato de discriminação. Nestes casos, o humor homofóbico é visto como cultural, como se pertencesse à cultura brasileira. Ou ainda, a redução da gravidade de tais falas discriminatórias se dá por parte de alguns(mas) entrevistados(as) ao associá-lo a outras causas que não o preconceito, seja reduzindo-o à infantilidade ou esvaziando o seu caráter ofensivo. Isto é problemático, já que torna a homofobia natural na companhia.

Todavia, as piadas homofóbicas servem como manutenção da heteronormatividade. Em tais discursos, pode-se perceber falas de pessoas que buscam pró-ativamente a criação de oportunidades para fazer piadas, em especial ao saberem de iniciativas anti-homofobia por parte da empresa. Notou-se também discursos que associam termos e atos tidos por femininos, a piada como forma de autoafirmação da suposta heterossexualidade e/ou masculinidade, a alta ocorrência de piadas homofóbicas em ambientes com muitos homens, a associação da homossexualidade a algo falho, ao feminino e a um aspecto negativo. A heteronormatividade é mantida e naturalizada por meio das piadas homofóbicas e atua em 
certos casos como base a construção do masculino na organização, reduzindo o masculino ao homem heterossexual.

Tendo em vista os resultados encontrados, é importante não apenas a promoção e inclusão da diversidade no espaço organizacional, mas a criação de ações que combatam o preconceito por orientação sexual nas empresas, como também o ensino por parte das ações de treinamento do que é o humor homofóbico, exemplificando que falas são ofensivas às pessoas homossexuais (como as sintetizadas nos exemplos do Quadro 1).

Na cultura brasileira o uso de piadas é algo presente no dia a dia, o que faz com que as pessoas tenham dificuldades de considerá-las como bullying direcionados a homossexuais (REIS; CARVALHO, 2014). Afinal, muitos funcionários desconhecem a associação de tais piadas à discriminação ou reduzem seu caráter ofensivo, naturalizando-as. Além disso, a criação de mecanismos que permitissem a denúncia por parte das vítimas de tais piadas poderia ser relevante para que estejam protegidas também desse tipo de discriminação e reduzisse a incidência com que são feitas. Tais ações poderiam ser importantes para que tais discursos agressivos e discriminatórios não continuem tendo seu valor distorcido a uma mera piada.

Este artigo contribui para o campo dos estudos organizacionais ao trazer à tona questões relacionadas a homofobia no ambiente de trabalho, principalmente por compreender este fenômeno por meio do humor e utilizando a abordagem da teoria queer nesta análise. Em termos de limitações da pesquisa, pode-se dizer que não possui possibilidade de generalização (dado que se trata de um estudo de caso) e a falta de mulheres homossexuais e bissexuais nas entrevistas pode trazer um resultado circunscrito à realidade masculina. Encorajamos estudos em outras organizações (pequeno e médio porte, privadas) sobre humor e heteronormatividade vivenciado também por mulheres.

\section{REFERÊNCIAS}

ARABSHEIBANI, G. R.; MARIN, A.; WADSWORTH, J. In the pink: homosexual-heterosexual wage differentials in the UK. International Journal of Manpower, v. 25, n. 3/4, p. 343-354, 2004.

ALLEGRETTO, S. A.; ARTHUR, M. M. An empirical analysis of homosexual/heterosexual male earnings differentials: unmarried and unequal? Industrial and Labor Relations Review, v. 54 , n. 3, p. 631-46, 2001.

BADGETT, M. V. L. The Wage effects of sexual orientation discrimination. Industrial and Labor Relations Review, v. 48, n. 4, p. 726-739, 1995.

BARDIN, L. Análise de conteúdo. Lisboa: Edições 70, 1977.

BIERNARCK, P.; WALDORF, D. Snowball Sampling: Problems and Techniques of Chain Referral Sampling. Sociological Methods \& Research, v. 10, n. 2, p. 141-163, 2016.

BORRILLO, D. A homofobia. In: LIONÇO, T.; DINIZ, D. (orgs.). Homofobia e Educação: um desafio ao silêncio. Brasília: LetrasLivres/EdUnB, 2009. 
BROWNE, K. Snowball sampling: using social networks to research non-heterosexual women. International Journal of Social Research Methodology, v. 8, n. 1, p. 47-60, 2005.

BUTLER, J. Gender trouble: feminism and the subversion of identity. New York: Routledge Classics, 1990.

CLAIN, S. H.; LEPPEL, K. An investigation into sexual orientation discrimination as an explanation for wage differences. Applied Economics, v. 33, p. 37-47, 2001.

COHEN, C. J. Punks, bulldaggers, and welfare queens: the radical potential of queer politics? GLQ, v. 3, p. 437-465, 1997.

COSTA, A. M. M. A discriminação por orientação sexual no trabalho: aspectos legais. In: POCAHY, F. Rompendo o silêncio: homofobia e heterossexismo na sociedade contemporânea. Políticas, teoria e atuação. Porto Alegre: NUANCES, 2007.

DUARTE, S. R.; DUARTE, L. C. R. P. O Humor nas Organizações: um Estudo Epistemológico. Revista Hospitalidade, v. 13, n. 2, p. 336-357, 2016.

FERREIRA, R. C. 0 gay no ambiente de trabalho: análise dos efeitos de ser gay nas organizações contemporâneas. 2007. Dissertação (Mestrado) Universidade de Brasília - UNB, Faculdade de Economia, Administração e Ciências da Informação e Documentação - FACE, Brasília, 2007.

FURTADO, R. A.; CARRIERI, A. P.; BRETAS, P. F. F. Humor na Internet: trabalhadores utilizam nova estratégia para protestar contra demissões e terceirizações. Revista de Administração, v. 49, n. 1, p. 33-44, 2014.

GARCIA, A.; SOUZA, E. M. Sexualidade e trabalho: estudo sobre a discriminação de homossexuais masculinos no setor bancário. Revista de Administração Pública. v. 44, n. 6, 2010.

HEBL, M. R. et al. Formal and interpersonal discrimination: a field study of bias toward homosexual applicants. Society for Personality and Social Psychology, v. 28, p. 815-825, 2002.

HEBL, M. R.; GRIFFITH, K. H. The disclosure dilemma for gay men and lesbians: "coming out" at work. Journal of Applied Psychology, v. 87, n. 6, p. 1191-1199, 2002.

HEREK, G. M. Stigma, prejudice, and violence against lesbians and gay men. In: GONSIOREK, J. C.; WEINRICH, J. D. Homosexuality: research implications for public policy. Newbury Park, California: Sage, 1991.

IRIGARAY, H. A. R.; SARAIVA, L. A. S.; CARRIERI, A. P. Humor e discriminação por orientação sexual no ambiente organizacional. Revista de Administração Contemporânea, v.14, n.5, p. 890-906, 2010.

JACKSON, S. Gender, sexuality and heterosexuality - the complecity (and limits) of heteronormativity. Feminist Theory, v. 7, n. 1, p. 105-121, 2006.

JUNQUEIRA, R. D. Homofobia: limites e possibilidades de um conceito em meio a disputas.

Revista Bagoas, v. 1, n. 1, p. 1-22, 2007.

KLAWITTER, M. Meta-analysis of the effects of sexual orientation on earnings. Industrial

Relations, v. 54, n.1, p. 4-32, 2015. 
LAURENT, T.; MIHOUBI, F. Sexual orientation and wage discrimination in France: the hidden side of the rainbow. Journal of Labor Research, v. 33, n. 4, p. 487-527, 2012.

LEE, H.; LEARMONTH, M.; HARDING, N. Quee(y)ing Public Administration. Public Administration, v. 86, n. 1, p. 149-167, 2008.

LIONÇO, T.; DINIZ, D. Homofobia, silêncio e naturalização: por uma narrativa da diversidade sexual. Psicologia Política, v. 8, n. 16, 2008.

LOURO, G. L. Um corpo estranho: ensaios sobre sexualidade e teoria queer. Belo Horizonte: Autêntica, 2004.

LYONS, H. Z. et al. A multicultural test of the theory of work adjustment: investigating the role of heterosexism and fit perceptions in the job satisfaction of lesbian, gay, and bisexual employees. Journal of Counseling Psychology, v. 52, n. 4, p. 537-548, 2005.

MEDEIROS, M. 0 trabalhador homossexual: o direito a identidade sexual e a não-discriminação no trabalho. In: POCAHY, F. Rompendo o silêncio: homofobia e heterossexismo na sociedade contemporânea. Políticas, teoria e atuação. Porto Alegre: Nuances, 2007.

MELO, F. V. S.; FARIAS, S. A.; KOVACS, M. H. Estereótipos e Estigmas de Obesos em Propagandas com Apelos de Humor. Organizações \& Sociedade, v. 24, n. 81, p. 305-324, 2017.

MICKES, L. et al. Who's funny: gender stereotypes, humor production, and memory bias. Psychon Bull Rev, n. 19, p. 108-112, 2012.

MOZZATO, A. R.; GRZYBOVSKI, D. Análise de conteúdo como técnica de análise de dados qualitativos no campo da Administração: potencial e desafios. Revista de Administração Contemporânea, v. 15, n. 4, p. 731-747, 2011.

O'CONNOR, E. C.; FORD, T. E.; BANOS, N. C. Restoring Threatened Masculinity: The Appeal of Sexist and Anti-Gay Humor. Sex Roles: A Journal of Research, v. 77, n. 9-10, p. 567-580, 2017.

PANAYIOTOU, A. 'Macho' managers and organizational heroes: competing masculinities in popular films. Organization, v. 17, n. 6, p. 659-683, 2010.

POCAHY, F. Um mundo de injúrias e outras violações. Reflexões sobre a violência heterossexual e homofóbica a partir da experiência do CRDH rompa o silêncio. In: POCAHY, F. Rompendo o silêncio: homofobia e heterossexismo na sociedade contemporânea. Políticas, teoria e atuação. Porto Alegre: Nuances, 2007.

RAGINS, B. R.; CORNWELL, J. M. Pink triangles: antecedentes and consequences of perceived workplace discrimination against gay and lesbian employees. Journal of Applied Psychology, v. 86, n. 6, p. 1244-1261, 2001.

REIS, A. F. R.; CARVALHO, G. Z. Homofobia e sexualidade: a agressividade do 'palavrão' como forma de manifestação do bullying no ambiente escolar. Interfaces na Educação, v. 5, n. 13, p. 194-207, 2014.

ROHM, R. H. D.; POMPEU, S. L. E. A homofobia como valor determinante nas práticas discriminatórias para a produção de subjetividades. Psicologia Política, v. 14, n. 30, p. 347-365, 2014. 
RUMENS, N.; BROOMFIELD, J. Gay men in the performing arts: Performing sexualities within 'gay-friendly' work contexts. Organization, v. 21, n. 3, p. 365-382, 2014.

SERDAHELY, W. J.; ZIEMBA, G. J. Changing homophobic atitudes through college sexuality education. Journal of Homossexuality, v. 10, n. 1-2, p. 109-116, 1984.

SILVA, R. R. C. C. Humor como Estratégia Discursiva na Compreensão da Dinâmica do Espaço Organizacional. Teoria e Prática em Administração, v. 6, n. 2, p. 54-77, 2016.

SIQUEIRA, M.V.S.; ZAULI-FELLOWS, A. Diversidade e identidade gay nas organizações. Revista Eletrônica de Gestão Organizacional, v. 4, n. 3, p. 69-81, 2006.

TYLER, M.; COHEN, L. Management in/as comic relief: Queer Theory and gender performativity in The Office. Gender, Work and Organization, v. 15, n. 2, p. 113-132, 2008.

WARD, J.; WINSTANLEY, D. Watching the Watch: The UK Fire Service and its Impact on Sexual Minorities in the Workplace. Gender, Work \& Organization, v. 13, n. 2, 2006.

WARNER, M. Introduction. In: WARNER, M. (ed.). Fear of a queer planet: queer politics and social theory. Minneapolis: University of Minnesota Press, 1993.

WEINBERG, G. Society and the Healthy Homosexual. New York: St. Martin's Press, 1972. WEAVER, S.; MORA, R. A.; MORGAN, K. Gender and humor: examining discourses of hegemony and resistance. Social Semiotics, v. 26, n. 3, p. 227-233, 2016.

WESTWOOD, R.; JOHNSTON, A. Reclaiming authentic sleves: control, resistive humor and identity work in the office. Organization, v. 19, n. 6, p. 787-808, 2011.

WOOD JR., T.; CALDAS, M. Rindo do que? Como consultores reagem ao humor crítico e à ironia sobre sua profissão. Organizações \& Sociedade, v. 12, n. 34, p. 83-101, 2005.

YANG, A. S. The polls-trends: attitudes toward homosexuality. Public Opinion Quarterly, v. 61, p. 477-507, 1997.

YIN, R. K. Estudo de caso: planejamento e métodos. 4. ed. Porto Alegre: Bookman, 2010.

Data de Submissão: 25/05/2017.

Data de Aprovação: 20/12/2017. 